\title{
Clinical impact of admission hypothermia in very low birth weight infants: results from Korean Neonatal Network
}

\author{
Na Hyun Lee, MD', Soo Kyung Nam, MD', Juyoung Lee, MD, PhD ${ }^{1,2}$, Yong Hoon Jun, MD, PhD ${ }^{1,2}$ \\ 'Department of Pediatrics, Inha University Hospital, Incheon, ${ }^{2}$ Department of Pediatrics, Inha University College of Medicine, Incheon, Korea
}

Background: Preterm infants have difficulty maintaining body temperature after birth. However, clinical guidelines advocate that neonatal body temperature should be maintained at $36.5^{\circ} \mathrm{C}-37.5^{\circ} \mathrm{C}$.

Purpose: We aimed to investigate the incidence of admission hypothermia in very low birth weight (VLBW) infants and to determine the association of admission temperature with in-hospital mortality and morbidities.

Methods: A cohort study using prospectively collected data involving 70 neonatal intensive care units (NICUs) that participate in the Korean Neonatal Network. From registered infants born between January 2013 and December 2015, 5,343 VLBW infants born at less than 33 weeks of gestation were reviewed. Results: The mean admission temperature was $36.1^{\circ} \mathrm{C} \pm 0.6^{\circ} \mathrm{C}$, with a range of $31.9^{\circ} \mathrm{C}$ to $38.4^{\circ} \mathrm{C}$. Approximately $74.1 \%$ of infants had an admission hypothermia of $<36.5^{\circ} \mathrm{C}$. Lower birth weight, intubation in the delivery room and Apgar score $<7$ at 5 minutes were significantly related to admission hypothermia. The mortality was the lowest at $36.5^{\circ} \mathrm{C}-37.5^{\circ} \mathrm{C}$ and adjusted odd ratios for all deaths increased to 1.38 (95\% confidence interval [Cl], 1.04-1.83), 1.44 (95\% Cl, 1.05-1.97) and 1.86 (95\% Cl, 1.22-2.82) for infants with admission temperatures of $36.0^{\circ} \mathrm{C}-36.4^{\circ} \mathrm{C}, 35.0^{\circ} \mathrm{C}-35.9^{\circ} \mathrm{C}$, and $<35.0^{\circ} \mathrm{C}$, respectively. Admission hypothermia was also associated with high likelihoods of bronchopulmonary dysplasia, pulmonary hypertension, proven sepsis, pulmonary hemorrhage, air-leak, seizure, grade 3 or higher intraventricular hemorrhage and advanced retinopathy of prematurity requiring laser therapy.

Conclusion: A large portion of preterm infants in Korea had hypothermia at NICU admission, which was associated with high mortality and several important morbidities. More aggressive interventions aimed at reducing hypothermia are required in this high-risk population.

Key words: Hypothermia, Intensive care units, Nenoatal, Infant, Premature

\section{Key message}

Question: Is low temperature at NICU admission associated with mortality and morbidities in preterm infants?

Finding: The mortality was the lowest at normothermia $\left(36.5^{\circ} \mathrm{C}-37.5^{\circ} \mathrm{C}\right)$ and increased with hypothermia at NICU admission. Admission hypothermia was also associated with bronchopulmonary dysplasia, pulmonary hypertension, sepsis, seizure, intraventricular hemorrhage, and retinopathy of prematurity. Meaning: More aggressive approaches are required to reduce admission hypothermia in preterm infants.

\section{Introduction}

Preterm infants have difficulty maintaining body temperature after birth, and hypothermia can occur easily as a result of their large surface area-to-body mass ratio and poor thermo-
Corresponding author: Juyoung Lee, MD, PhD Department of Pediatrics, Inha University College of Medicine, 27 Inhang-ro, Jung-gu, Incheon 22332, Korea

Tel: +82-32-890-3506

Fax: +82-32-890-2844

E-mail: juyounglee@inha.ac.kr

https://orcid.org/0000-0001-7548-2284

Received: 26 February, 2019

Revised: 19 April, 2019

Accepted: 22 May, 2019
Copyright (C) 2019 by The Korean Pediatric Society

This is an open-access article distributed under the terms of the Creative Commons Attribution NonCommercial License (http://creativecommons.org/ licenses/by-nc/4.0/) which permits unrestricted noncommercial use, distribution, and reproduction in any medium, provided the original work is properly cited. 
regulation. ${ }^{1,2)}$ The World Health Organization (WHO) classifies $36.0^{\circ} \mathrm{C}$ to $36.4^{\circ} \mathrm{C}$ as cold stress or mild hypothermia, $32.0^{\circ} \mathrm{C}$ to $35.9^{\circ} \mathrm{C}$ as moderate hypothermia, and lower than $32.0^{\circ} \mathrm{C}$ as severe hypothermia, and the WHO advocates that neonatal body temperature should be maintained at $36.5^{\circ} \mathrm{C}$ to $37.5^{\circ} \mathrm{C}$. ${ }^{3)}$ In 2012 , the American Academy of Pediatrics/American College of Obstetricians and Gynecologists distributed guidelines recommending an axillary temperature range of $36.5^{\circ} \mathrm{C}$ to $37.4^{\circ} \mathrm{C}$ in the delivery room (DR). ${ }^{4)}$ Hypothermia has been confirmed to be significantly related to mortality $^{5}$ and morbidities, including necrotizing enterocolitis (NEC) ${ }^{5-8)}$ intraventricular hemorrhage (IVH) ${ }^{9)}$ and late-onset sepsis ${ }^{8}$ in preterm infants. To reduce these complications, many studies have suggested ways to prevent hypothermia, including plastic wrapping without drying, covering the head with a cap, and using radiant warmers and exothermic mattresses. ${ }^{10-13)}$ Despite the knowledge and development of new approaches to better maintain body temperature, recent studies have noted that a significant proportion of preterm infants in high-resource countries have failed to maintain normothermia after delivery. ${ }^{7,914-18)}$ With the marked improvement of intensive care for preterm infants over the past few decades, mortality and main morbidities of very low birth weight (VLBW) infants have decreased in Korea but are still higher than those in the United States, Europe, and Japan. ${ }^{19,20}$ We aimed to investigate the incidence of admission hypothermia in VLBW infants using the Korean national registry data and to determine the association of admission temperature with in-hospital mortality and morbidities.

\section{Methods}

\section{Study participants and outcomes}

We performed a cohort study using prospectively collected data from 70 neonatal intensive care units (NICUs) participating in the Korean Neonatal Network (KNN). The KNN database provides maternal, delivery, and neonatal data until the first NICU discharge, and the data are collected by trained staff using a standardized operating procedure. ${ }^{21)}$ The registration of data in the KNN was approved by the Institutional Review Board of each participating center (approval number: 2013-03-002). Informed consent was obtained from the parents of each infant prior to participation in the KNN registry.

From 5,860 registered VLBW infants between January 1, 2013, and December 31, 2015, we included 5,343 infants born at less than 33 weeks of gestation. To reduce the effects of other causes on study outcomes, we excluded infants with congenital respiratory, gastrointestinal or cardiovascular anomalies. Infants who had no data on admission temperature measured within 1 hour after the birth or who were transferred to other hospitals were also excluded. The admission temperature was defined as the infant's axillary or rectal temperature measured on admission to the NICU within
1 hour after birth, in accordance with local routines. Because the WHO classification of moderate hypothermia includes a large range of temperature $\left(32.0^{\circ} \mathrm{C}-35.9^{\circ} \mathrm{C}\right)$ and severe hypothermia $\left(<32.0^{\circ} \mathrm{C}\right)$ is extremely rare, we divided included infants into 5 groups according to their admission temperature: $<35.0^{\circ} \mathrm{C}, 35.0^{\circ} \mathrm{C}-35.9^{\circ} \mathrm{C}$, $36.0^{\circ} \mathrm{C}-36.4^{\circ} \mathrm{C}, 36.5^{\circ} \mathrm{C}-37.5^{\circ} \mathrm{C}$, and $>37.5^{\circ} \mathrm{C}$.

The maternal variables included diabetes, pregnancy-induced hypertension, histological chorioamnionitis, rupture of the membranes ( $>24$ hours), cesarean section, and oligohydramnios. The neonatal variables included singleton or not, gender, gestational age, birth weight, small for gestational age, Apgar score at 5 minutes, immediate resuscitation at delivery including intubation, chest compressions and use of surfactant at the DR, immediate postnatal blood gas analysis results (measured within 1 hour after birth), pulmonary hemorrhage, pulmonary air-leak, bronchopulmonary dysplasia (BPD), pulmonary hypertension, NEC, bacterial sepsis, hypotension, seizure, IVH, periventricular leukomalacia (PVL), retinopathy of prematurity (ROP), automated auditory brainstem response (AABR) test results before NICU discharge, cumulative duration of invasive mechanical ventilation and parenteral nutrition, and survival to hospital discharge or death. We identified the time of death for infants who died (death before or after 28 days). The most severe stage of IVH was based on the results of all brain ultrasound findings until the first NICU discharge was recorded regardless of the time of first observation or occurrence, as this information was not collected. IVH grading was determined according to Papile's classification. ${ }^{22)}$ NEC was defined according to a modified Bell staging classification. Bacterial sepsis was defined as a positive result on 1 or more bacterial cultures obtained from the blood of infants with clinical signs of infection or those treated with appropriate antibiotics for 5 or more days or until death. Pulmonary hypertension was considered present only when accompanied by medical treatment after diagnosis based on echocardiography. PVL was diagnosed based on the results of brain ultrasound or magnetic resonance imaging findings. The duration of mechanical ventilation was counted as each day that the infant received any respiratory support through an endotracheal tube because of respiratory insufficiency. Brief intubation for surgery with general anesthesia was not included in the calculation of mechanical ventilation duration. The duration of parenteral nutrition was the sum of the total number of days when any amino acids or lipids were provided intravenously before death or discharge.

The primary outcome was survival to hospital discharge or death. Secondary outcomes were the various in-hospital morbidities, including BPD, defined as the need for supplemental oxygen or positive pressure support at 36 weeks of postmenstrual age; grade 3 or $4 \mathrm{IVH}$; stage 2 or higher NEC; culture-proven bacterial sepsis or meningitis at older than 48 hours; PVL and advanced ROP followed by laser coagulation. 
Table 1. Characteristics of included infants $(n=4,673)$

\begin{tabular}{|c|c|}
\hline Characteristic & Value \\
\hline \multicolumn{2}{|l|}{ Maternal information } \\
\hline Diabetes & $392(8.4)$ \\
\hline Hypertension & $882(18.9)$ \\
\hline Histological chorioamnionitis & $1,396(29.9)$ \\
\hline Rupture of membranes, $>24 \mathrm{hr}$ & $1,749(37.4)$ \\
\hline Cesarean section & $3,523(75.4)$ \\
\hline Oligohydramnios & $576(12.3)$ \\
\hline \multicolumn{2}{|l|}{ Infant information } \\
\hline Singleton & $3,036(65.0)$ \\
\hline Sex, boy:girl & 2,374 (50.8):2,299 (49.2) \\
\hline Inborn & 4,596 (98.4) \\
\hline Apgar score $<5$ at 5 min & $692(14.8)$ \\
\hline Apgar score $<7$ at 5 min & $1,826(39.1)$ \\
\hline Any resuscitation at delivery & $4,277(91.5)$ \\
\hline Intubation at delivery & $3,252(69.6)$ \\
\hline Chest compression at delivery & $218(4.7)$ \\
\hline Surfactant at delivery room & $2,738(58.6)$ \\
\hline Gestational age (wk) & $28.6(26.4-30.1)$ \\
\hline Birth weight (g) & $1,080(840-1,300)$ \\
\hline Birth weight $z$ score & $-0.07(-0.75-0.45)$ \\
\hline Small for gestational age, $<3$ rd percentile & $201(4.3)$ \\
\hline Small for gestational age, 3rd-10th percentile & $395(8.5)$ \\
\hline
\end{tabular}

Values are presented as number (\%) or median (interquartile range).

\section{Statistical analysis}

Demographic data are expressed as medians (interquartile ranges) or percentages. For univariate analysis, we used the Kruskal-Wallis analysis or chi-square test. We then evaluated the odds ratios (ORs) according to admission temperature using multivariate logistic regression analysis, with adjustment for factors that had a $P<0.1$ in the univariate analysis. We also estimated curves for mortality according to the admission temperature. $P<0.05$ was considered significant. Statistical analyses were conducted using IBM SPSS Statistics ver. 21.0 (IBM Co., Armonk, NY, USA).

\section{Results}

Of the 5,343 included infants, 670 infants (12.5\%) were excluded for having congenital anomalies $(n=127)$ or no data on admission temperature $(n=243)$ or for being transferred to other hospitals before the first discharge $(n=300)$. The remaining 4,673 infants were included in this analysis, and their characteristics are described in Table 1. Their median gestational age and birth weight were 28.6 weeks and 1,080 g, respectively. Of the 4,673 neonates, $12.8 \%$ were small for gestational age. A large proportion of infants were delivered by cesarean section (75.4\%) and had been intubated in the DR (69.6\%).

The mean ( \pm standard deviation) admission temperature was $36.1^{\circ} \mathrm{C}\left( \pm 0.6^{\circ} \mathrm{C}\right)$, with a range of $31.9^{\circ} \mathrm{C}$ to $38.4^{\circ} \mathrm{C}$. Only $25.2 \%$ of infants had a normal admission temperature between $36.5^{\circ} \mathrm{C}$ and

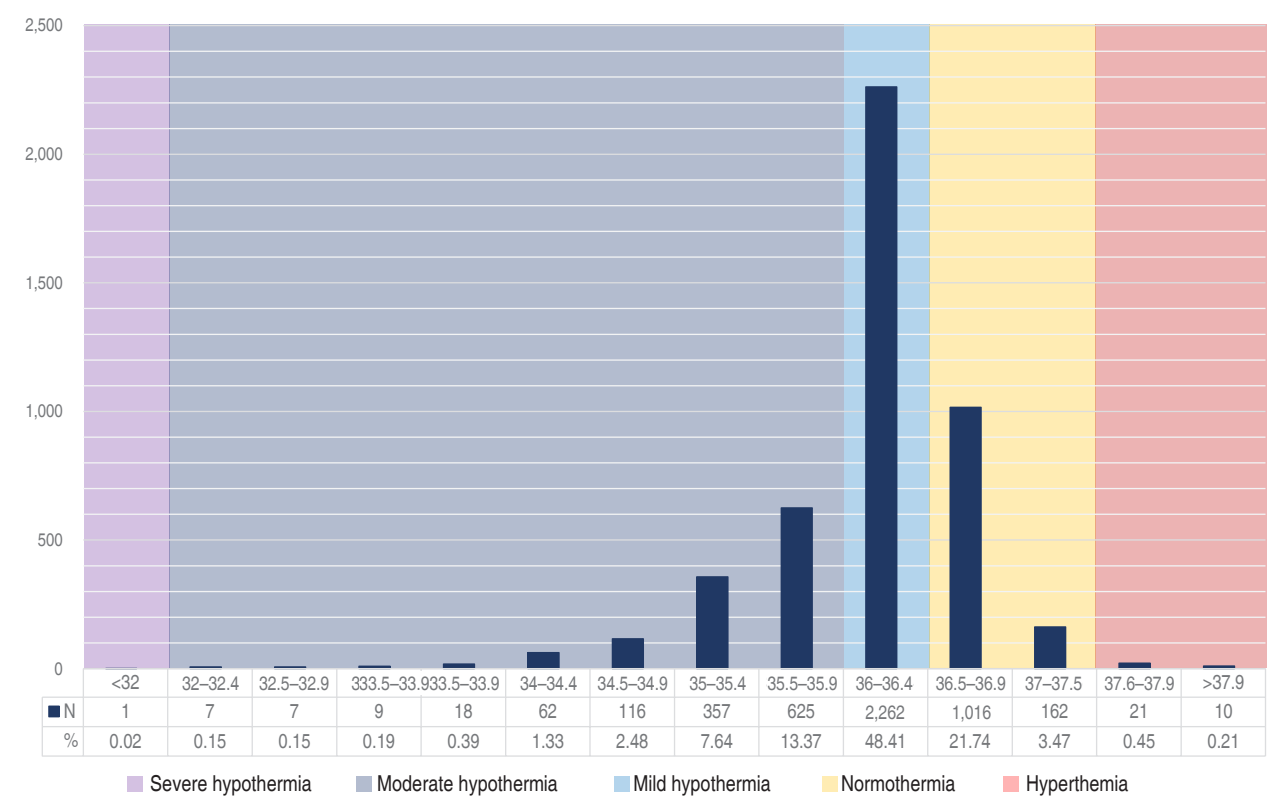

Fig. 1. Admission temperature distribution. Only $25.2 \%$ of infants had a normal admission temperatures ranging from $36.5^{\circ} \mathrm{C}$ to $37.5^{\circ} \mathrm{C}$. Approximately $74.1 \%$ of infants had hypothermia $<36.5^{\circ} \mathrm{C}$, and $0.66 \%$ had hyperthermia $>37.5^{\circ} \mathrm{C}$ at neonatal intensive care unit admission. 
$37.5^{\circ} \mathrm{C}$ (Fig. 1). Approximately $74.1 \%$ of infants had an admission temperature lower than $36.5^{\circ} \mathrm{C}$, and $0.7 \%$ had an admission temperature higher than $37.5^{\circ} \mathrm{C}$ (Fig. 1). Approximately half of the study population (48.4\%) had mild hypothermia ranging from $36.0^{\circ} \mathrm{C}$ to $36.4^{\circ} \mathrm{C}$ at admission to the NICU, and a quarter of the study population (25.7\%) had moderate hypothermia ranging from $32.0^{\circ} \mathrm{C}$ to $35.9^{\circ} \mathrm{C}$. Fig. 2 shows the distribution of admission temperatures according to the gestational age of the infants. Normal admission temperatures $\left(36.5^{\circ} \mathrm{C}-37.5^{\circ} \mathrm{C}\right)$ were noted in less than $10 \%$ of infants born before 24 weeks of gestation. Although profound hypothermia less than $34^{\circ} \mathrm{C}$ was observed only in infants born at less than 28 weeks of gestation, the proportion of infants with normal admission temeratures was similar among those born from 26 to 32 weeks of gestation.

The demographic characteristics of each group are provided in Table 2. Gestational age, birth weight, small for gestational age, delivery by cesarean section, Apgar score $<7$ at 5 minutes, intubation in the DR, maternal oligohydramnios, premature rupture of the membranes and chorioamnionitis were associated with admission temperature in the univariate analysis. The multivariate analysis showed that lower birth weight and intubation in the DR were significantly related to admission hypothermia, and an Apgar score of less than 7 at 5 min increased the risks of both hypothermia and hyperthermia at NICU admission (Table 3).

The primary outcome, all mortality, was significantly associated with the admission temperature. Compared with infants with normothermia $\left(36.5^{\circ} \mathrm{C}-37.5^{\circ} \mathrm{C}\right)$, the adjusted ORs for all deaths increased to 1.38 (95\% confidence interval [CI], 1.04-1.83), 1.44 (95\% CI, 1.05-1.97), and 1.86 (95\% CI, 1.22-2.82) for infants with admission hypothermia of $36.0^{\circ} \mathrm{C}-36.4^{\circ} \mathrm{C}, 35.0^{\circ} \mathrm{C}-35.9^{\circ} \mathrm{C}$, and $<35.0^{\circ} \mathrm{C}$, respectively (Table 4). The mortality in infants with an admission temperature of $>37.5^{\circ} \mathrm{C}$ did not differ from those with normothermia (Table 4). When dividing mortality according to the time of death, the adjusted ORs of death before 28 days increased to 1.40 (95\% CI, 1.02-1.92) and 2.16 (95\% CI, 1.39-3.34) for infants with temperatures of $35.0^{\circ} \mathrm{C}-35.9^{\circ} \mathrm{C}$ and $<35.0^{\circ} \mathrm{C}$ at NICU admission, respectively. Death after 28 days was not associated with admission hypothermia (Table 4). When we estimated the curve for mortality according to admission temperature, the curve was represented by a second-order equation and was statistically significant $(P<0.001)$ (Fig. 3). Mortality was the lowest at admission temperatures ranging from $36.5^{\circ} \mathrm{C}$ to $37.5^{\circ} \mathrm{C}$.

The univariate analysis of the clinical influence of admission temperature indicated that pulmonary hemorrhage, air-leak, BPD, pulmonary hypertension, stage 2 or higher NEC, culture-proven sepsis, hypotension, grade 3 or higher IVH, advanced ROP requiring laser surgery, abnormal AABR test results, and the duration of parenteral nutrition and mechanical ventilation, but not PVL, were associated with admission temperature (Table 2). In the multivariate analysis, admission hypothermia was associated with pulmonary hemorrhage, air-leak, BPD at 36 weeks, pulmonary hypertension, proven sepsis, seizure, high-grade IVH, and advanced ROP requiring laser therapy (Table 4). Compared with infants who were normothermic $\left(36.5^{\circ} \mathrm{C}-37.5^{\circ} \mathrm{C}\right)$, the adjusted $\mathrm{OR}$ of BPD and pulmonary hypertension increased to 1.26 (95\% CI, 1.01-1.57) and 1.66 (95\% CI, 1.12-2.45) for infants with admission temperatures of $35.0^{\circ} \mathrm{C}-35.9^{\circ} \mathrm{C}$ and 1.81 (95\% CI, 1.20-2.86) and 1.75 (95\% CI, 1.06$2.87)$ for infants with admission temperatures $<35.0^{\circ} \mathrm{C}$. The adjusted ORs of sepsis increased to 1.27 (95\% CI, 1.05-1.54), 1.39 (95\% CI, 1.07-1.78), and 1.74 (95\% CI, 1.51-2.08) for infants with admission temperatures of $36.0^{\circ} \mathrm{C}-36.4^{\circ} \mathrm{C}, 35.0^{\circ} \mathrm{C}-35.9^{\circ} \mathrm{C}$, and $<35.0^{\circ} \mathrm{C}$, respectively. For pulmonary hemorrhage, air-leak, seizure, IVH grade

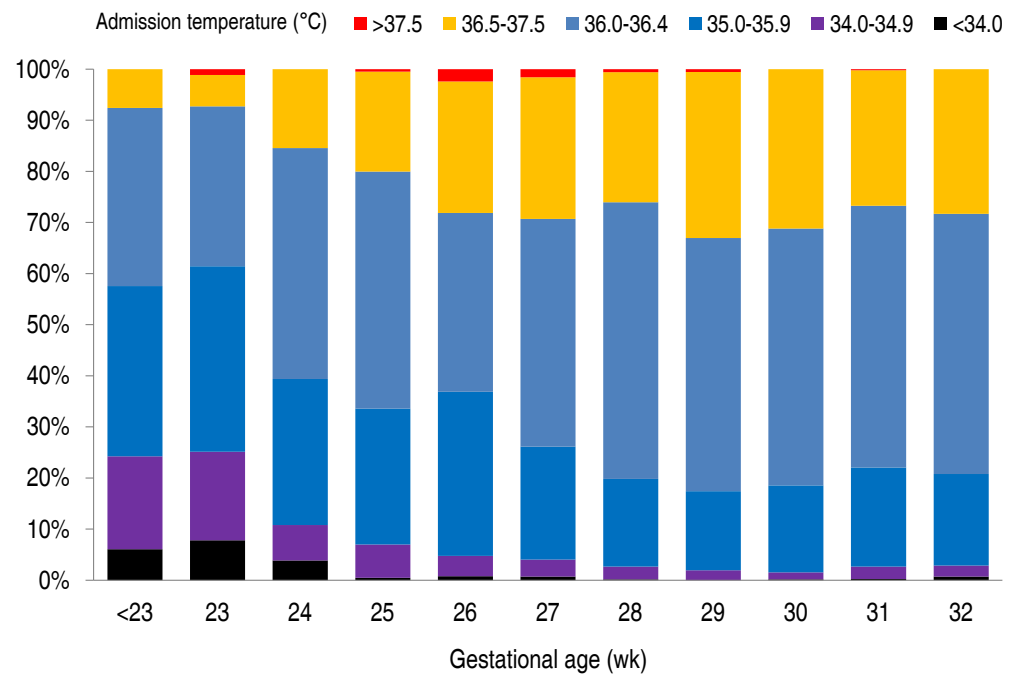

Fig. 2. Admission temperature distribution according to gestational age. Distributions of infants across the range of temperatures recorded according to gestational age. 
Table 2. Univariate analysis of associations between characteristics and admission temperatures

\begin{tabular}{|c|c|c|c|c|c|c|}
\hline \multirow{2}{*}{ Variable } & \multicolumn{5}{|c|}{ Admission temperature $\left({ }^{\circ} \mathrm{C}\right)$} & \multirow{2}{*}{$P$ value ${ }^{\text {a) }}$} \\
\hline & $<35.0(n=220)$ & $35.0-35.9(n=982)$ & $36.0-36.4(n=2,262)$ & $36.5-37.5(n=1,178)$ & $>37.5(\mathrm{n}=31)$ & \\
\hline Boy & $115(52.3)$ & $509(51.8)$ & $1,119(49.5)$ & $611(51.9)$ & $20(64.5)$ & 0.279 \\
\hline Singleton & $136(61.8)$ & $644(65.6)$ & $1,445(63.9)$ & 795 (67.5) & $16(51.6)$ & 0.091 \\
\hline Gestational age (wk) & $25.6(23.9-28.2)$ & 27.7 (25.7-29.9) & $28.7(26.7-30.1)$ & $29.0(27.4-30.3)$ & $27.6(26.4-28.3)$ & $<0.001$ \\
\hline Birth weight (g) & 725 (560-964) & $990(740-1,240)$ & $1,090(860-1,300)$ & $1,190(970-1,370)$ & $1,050(830-1,120)$ & $<0.001$ \\
\hline SGA & $48(21.8)$ & $155(15.8)$ & $284(12.6)$ & $108(9.2)$ & $1(3.2)$ & $<0.001$ \\
\hline Cesarean section & $159(72.3)$ & $758(77.2)$ & $1,737(76.8)$ & $850(72.2)$ & $19(61.3)$ & 0.004 \\
\hline Oligohydramnios & 43 (19.5) & $123(12.5)$ & $268(11.8)$ & $138(11.7)$ & 4 (12.9) & 0.021 \\
\hline Maternal PROM & 89 (40.5) & $312(31.8)$ & $848(37.5)$ & $483(41.0)$ & $17(54.8)$ & $<0.001$ \\
\hline Chorioamnionitis & 78 (35.5) & $314(32.0)$ & $631(27.9)$ & $355(30.1)$ & $18(58.1)$ & $<0.001$ \\
\hline $\mathrm{AS}<7$ at $5 \mathrm{~min}$ & 79 (35.9) & $319(32.5)$ & 858 (37.9) & $564(47.9)$ & $6(19.4)$ & $<0.001$ \\
\hline Intubation at DR & $195(88.6)$ & $775(78.9)$ & $1,571(69.5)$ & $686(58.2)$ & $25(80.6)$ & $<0.001$ \\
\hline pH, postnatal $<1 \mathrm{hr}$ & $7.24(7.12-7.29)$ & $7.26(7.20-7.32)$ & 7.28 (7.22-7.35) & $7.28(7.21-7.35)$ & $7.28(7.20-7.32)$ & $<0.001$ \\
\hline Base excess, postnatal $<1 \mathrm{hr}$ & $-7.0(-10.0$ to -4.3$)$ & $-5.0(-7.6$ to -2.7$)$ & $-4.4(-7.0$ to -2.2$)$ & $-4.1(-7.0$ to -2.0$)$ & $-4.3(-8.4$ to -1.9$)$ & $<0.001$ \\
\hline Pulmonary hemorrhage & $27(12.3)$ & $95(9.7)$ & $150(6.6)$ & $48(4.1)$ & $0(0)$ & $<0.001$ \\
\hline Air-leak & $34(15.5)$ & $83(8.5)$ & $121(5.3)$ & $46(3.9)$ & $0(0)$ & $<0.001$ \\
\hline $\mathrm{BPD}, 0^{2}$ at PMA 36 wk & $75(55.1)$ & $303(37.2)$ & $573(28.7)$ & $259(23.5)$ & $11(37.9)$ & $<0.001$ \\
\hline Pulmonary hypertension & $41(18.6)$ & $100(10.2)$ & $151(6.7)$ & $46(3.9)$ & $1(3.2)$ & $<0.001$ \\
\hline NEC, $\geq$ stage 2 & $23(10.5)$ & $77(7.8)$ & $133(5.9)$ & $46(3.9)$ & $0(0)$ & $<0.001$ \\
\hline Sepsis & $53(24.1)$ & $233(23.7)$ & $505(22.3)$ & $189(16.0)$ & $9(29.0)$ & $<0.001$ \\
\hline Hypotension & $110(50.0)$ & $292(29.7)$ & $543(24.0)$ & $223(19.8)$ & $8(25.8)$ & $<0.001$ \\
\hline Seizure & $51(23.2)$ & $108(11.0)$ & $203(9.0)$ & $65(5.5)$ & $1(3.2)$ & $<0.001$ \\
\hline $\mathrm{IVH}, \geq$ grade 3 & $50(25.0)$ & $109(11.7)$ & $194(8.9)$ & $74(6.4)$ & $3(10.0)$ & $<0.001$ \\
\hline PVL & $20(9.1)$ & $91(9.3)$ & $191(8.4)$ & $75(6.4)$ & $2(6.5)$ & 0.121 \\
\hline ROP & $22(10.0)$ & $96(9.8)$ & $179(7.9)$ & $64(5.4)$ & $2(6.5)$ & 0.003 \\
\hline Abnormal AABR & $32(28.1)$ & $136(18.7)$ & $213(12.0)$ & $148(14.2)$ & $7(25.0)$ & $<0.001$ \\
\hline Parenteral nutrition (day) & $\mathrm{a} 0$ (9-39) & $20(10-37)$ & $18(10-33)$ & 16 (9-29) & $22(12-33)$ & $<0.001$ \\
\hline Mechanical ventilation (day) & $11(4-34)$ & $6(1-26)$ & $4(1-18)$ & $3(1-12)$ & $6(2-13)$ & $<0.001$ \\
\hline Death, total & $86(39.1)$ & 189 (19.2) & $294(13.0)$ & $87(7.4)$ & $3(9.7)$ & $<0.001$ \\
\hline Death, $<28$ day & $76(34.5)$ & $136(13.8)$ & $222(9.8)$ & $64(5.4)$ & $2(6.5)$ & $<0.001$ \\
\hline Death, $>28$ day & $10(4.5)$ & $53(5.4)$ & 72 (3.2) & $23(2.0)$ & $1(3.2)$ & $<0.001$ \\
\hline
\end{tabular}

Values are presented as number (\%) or median (interquartile range).

SGA, small for gestational age; PROM, premature rupture of membrane; AS, Apgar score; DR, delivery room; BPD, bronchopulmonary dysplasia; PMA, postmenstrual age; NEC, necrotizing enterocolitis; IVH, intraventricular hemorrhage; PVL, periventricular leukomalacia; ROP, retinopathy of prematurity; AABR, automated auditory brainstem response.

a)Kruskal-Wallis or chi-square test. ${ }^{\text {b) }}$ Histological chorioamnionitis confirmed by placental biopsy.

3 or 4 and advanced ROP requiring laser, significantly higher ORs were observed in infants with admission temperatures $<35^{\circ} \mathrm{C}$ than in normothermic infants. NEC stage $\geq 2$, PVL and abnormal AABR test results were not significantly correlated with admission temperature in the multivariate analysis (Table 4).

\section{Discussion}

This is the first large national cohort study to investigate the incidence of admission hypothermia and its association with in-hospital mortality and morbidities in Korea. From the estimated curve, we would be able to predict individual mortality according to admission temperature. Despite general enhancements in perinatal intensive care and many studies showing the relationship of admission hypothermia with neonatal mortality, we found that admission hypothermia $\left(<36.5^{\circ} \mathrm{C}\right)$ is still common in Korea, occurring in $74.1 \%$ of VLBW and less than 33 weeks preterm infants. The proportion of infants with normal temperature ranges at NICU admission (25.2\%) was much lower than those in other developed countries: 48.8\% in a Brazilian cohort of less than 34 weeks, ${ }^{17)} 57.2 \%$ in a Canadian cohort of less than 33 weeks $^{8)}$ and $42.2 \%$ in a European cohort of less than 
Table 3. Logistic regression analysis for independent variables associated with the admission temperatures

\begin{tabular}{lccccc}
\hline \multirow{2}{*}{ Variable } & \multicolumn{5}{c}{ Adjusted $\mathrm{OR}^{\mathrm{a})}(95 \% \mathrm{Cl})$ according to the admission temperature $\left(^{\circ} \mathrm{C}\right)$} \\
\cline { 2 - 6 } & $<35.0$ & $35.0-35.9$ & $36.0-36.4$ & $36.5-37.5$ & $>37.5$ \\
\hline Gestational age & $0.971(0.845-1.115)$ & $0.996(0.919-1.078)$ & $1.097(0.999-1.024)$ & 1.00 & $1.066(0.766-1.483)$ \\
Birth weight & $0.996(0.994-0.997)$ & $0.998(0.997-0.999)$ & $0.998(0.998-0.999)$ & 1.00 & $0.998(0.995-1.001)$ \\
SGA & $1.110(0.600-2.055)$ & $0.936(0.636-1.377)$ & $1.232(0.889-1.708)$ & 1.00 & $1.974(0.313-12.46)$ \\
Cesarean section & $0.948(0.662-1.358)$ & $0.836(0.675-1.035)$ & $0.885(0.746-1.051)$ & 1.00 & $1.830(0.884-3.786)$ \\
Oligohydramnios & $0.747(0.493-1.131)$ & $1.019(0.771-1.346)$ & $1.069(0.850-1.345)$ & 1.00 & $1.012(0.372-2.755)$ \\
Maternal PROM & $1.070(0.767-1.492)$ & $1.494(0.998-1.814)$ & $1.077(0.922-1.257)$ & 1.00 & $0.689(0.334-1.423)$ \\
Chorioamnionitis & $1.063(0.762-1.482)$ & $0.935(0.766-1.142)$ & $1.086(0.921-1.281)$ & 1.00 & $0.489(0.238-1.006)$ \\
AS <7 at 5 min & $2.135(1.560-2.921)$ & $2.168(1.806-2.603)$ & $1.582(1.368-1.830)$ & 1.00 & $4.977(2.035-12.17)$ \\
Intubation in DR & $1.594(1.007-2.602)$ & $1.757(1.405-2.197)$ & $1.421(1.197-1.687)$ & 1.00 & $1.974(0.729-4.805)$ \\
\hline
\end{tabular}

OR, odds ratio; $\mathrm{Cl}$, confidence interval; SGA, small for gestational age; PROM, premature rupture of the membrane; AS, Apgar score; DR, delivery room.

${ }^{a}$ Adjusted with maternal premature rupture of membrane, cesarean section, oligohydramnios, chorioamnionitis, gestational age, birth weight, small for gestational age, Apgar score $<7$ at 5 min, intubation in the delivery room.

Table 4. Multivariate analysis of the association between death and admission temperatures

\begin{tabular}{|c|c|c|c|c|c|}
\hline \multirow{2}{*}{ Variable } & \multicolumn{5}{|c|}{ Adjusted $\mathrm{OR}^{\mathrm{a})}(95 \% \mathrm{Cl})$ according to the admission temperature $\left({ }^{\circ} \mathrm{C}\right)$} \\
\hline & $<35.0$ & $35.0-35.9$ & $36.0-36.4$ & $36.5-37.5$ & $>37.5$ \\
\hline Death, total & $1.86(1.22-2.82)$ & $1.44(1.05-1.97)$ & $1.38(1.04-1.83)$ & 1.00 & $0.87(0.28-2.75)$ \\
\hline Death, $\leq 28$ day & $2.16(1.39-3.34)$ & $1.40(1.02-1.92)$ & $1.27(0.90-1.80)$ & 1.00 & $0.55(0.12-2.48)$ \\
\hline Death, $>28$ day & $0.67(0.30-1.49)$ & $1.60(0.94-1.97)$ & $1.20(0.73-1.97)$ & 1.00 & $1.93(0.42-8.96)$ \\
\hline Pulmonary hemorrhage & $1.50(1.02-2.20)$ & $1.18(0.69-2.02)$ & $1.33(0.94-1.88)$ & 1.00 & $0.95(0.22-4.17)$ \\
\hline Air-leak & $1.72(1.04-2.86)$ & $1.41(0.95-2.08)$ & $1.12(0.79-1.60)$ & 1.00 & - \\
\hline $\mathrm{BPD}, 0^{2}$ at PMA $36 \mathrm{wk}$ & $1.81(1.20-2.74)$ & $1.26(1.01-1.57)$ & $1.09(0.91-1.32)$ & 1.00 & $0.71(0.33-1.54)$ \\
\hline Pulmonary hypertension & $1.75(1.06-2.87)$ & $1.66(1.12-2.45)$ & $1.43(0.99-2.05)$ & 1.00 & $1.28(0.36-4.58)$ \\
\hline NEC, $\geq$ stage 2 & $1.13(0.65-1.98)$ & $1.34(0.90-1.99)$ & $1.22(0.86-1.74)$ & 1.00 & - \\
\hline Sepsis & $1.74(1.51-2.08)$ & $1.39(1.07-1.78)$ & $1.27(1.05-1.54)$ & 1.00 & $1.38(0.67-2.84)$ \\
\hline Seizure & $1.67(1.07-2.60)$ & $1.18(0.84-1.66)$ & $1.34(0.99-1.82)$ & 1.00 & $0.26(0.03-1.95)$ \\
\hline $\mathrm{IVH}, \geq$ grade 3 & $1.62(1.02-2.55)$ & $1.12(0.80-1.57)$ & $1.14(0.85-1.53)$ & 1.00 & $1.15(0.38-3.47)$ \\
\hline PVL & $1.22(0.71-2.08)$ & $1.32(0.95-1.84)$ & $1.28(0.96-1.69)$ & 1.00 & $0.97(0.29-3.24)$ \\
\hline ROP & 2.25 (1.29-3.92) & $1.09(0.76-1.56)$ & $0.89(0.65-1.22)$ & 1.00 & $1.95(0.44-8.69)$ \\
\hline Abnormal AABR & $1.47(0.92-2.34)$ & $1.07(0.82-1.40)$ & $0.72(0.57-1.91)$ & 1.00 & $0.98(0.42-2.32)$ \\
\hline
\end{tabular}

$\mathrm{OR}$, odds ratio; $\mathrm{Cl}$, confidence interval; BPD, bronchopulmonary dysplasia; PMA, postmenstrual age; NEC, necrotizing enterocolitis; IVH, intraventricular hemorrhage; PVL, periventricular leukomalacia; ROP, retinopathy of prematurity; AABR, automated auditory brainstem response.

${ }^{a}$ adjusted with maternal premature rupture of membrane, cesarean section, oligohydramnios, chorioamnionitis, gestational age, birth weight, small for gestational age, Apgar score $<7$ at $5 \mathrm{~min}$, intubation in the delivery room.

32 weeks. ${ }^{18)}$ More concerning is that the proportion of infants with hypothermia below $36.0^{\circ} \mathrm{C}$ was $25.7 \%$ in this Korean cohort compared to $11.9 \%$ in a Canadian cohort ${ }^{8)}$ and $22.3 \%$ in a European cohort. $^{18)}$

Unfortunately, we did not include a comparison between centers. There might be large variations in the incidences and proportions of admission hypothermia among centers, which would be deter mined by the DR temperature and the policies of each center for preventing hypothermia at delivery. However, the DR temperature or thermoregulation policies of each center were not included in these cohort data, and the Korean Centers for Disease Control and Prevention did not permit individual data of each center to be eval- uated. From the report of one center belonging to the KNN located in Seoul, which had a smaller proportion of infants (54.9\%) with admission hypothermia $\left(<36.5^{\circ} \mathrm{C}\right)$ than our national data $(74.1 \%),{ }^{23)}$ we can infer that the center-to-center difference would be large.

The key area to reduce admission hypothermia is in the DR. This hypothesis is supported by our results that a low Apgar score at 5 minutes and intubation in the DR were independently related to a lower admission temperature (Table 3). Infants who require resuscitation are usually sicker, and warming infants in the midst of resuscitation is difficult or neglected. According to the Neonatal Resuscitation Program guidelines, ${ }^{10)}$ the temperature of the DR should be $23^{\circ} \mathrm{C}$ to $25^{\circ} \mathrm{C}$ for all preterm newborns and $25^{\circ} \mathrm{C}$ or higher 


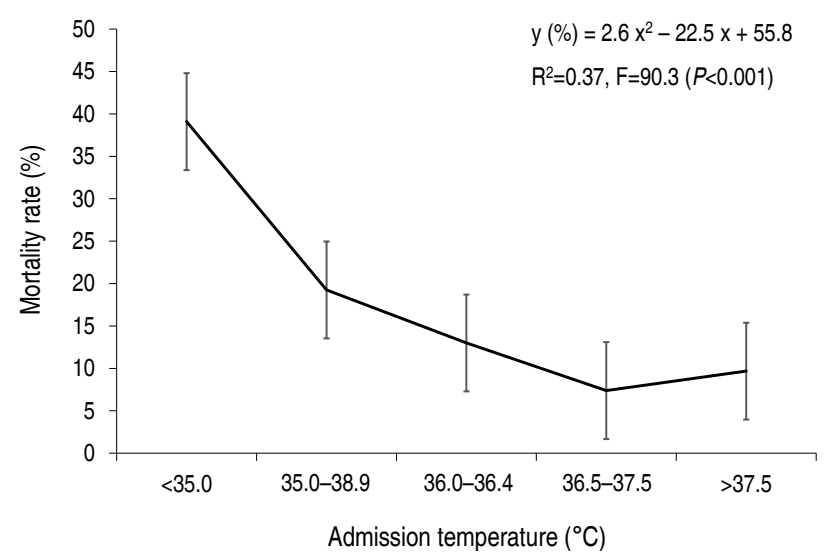

Fig. 3. Association of admission temperature with mortality rate. This curve represents the association of admission temperature with a mortality rate as a second-order equation. Mortality was the lowest at an admission temperature of $36.5^{\circ} \mathrm{C}-37.5^{\circ} \mathrm{C}(P<0.001)$.

for neonates less than 28 weeks of gestation. The American Colleges of Obstetricians and Gynecologists recommends prewarming of the DR to $26^{\circ} \mathrm{C}$ for neonates requiring any resuscitation. ${ }^{4)}$ In addition, other warming techniques should be performed to decrease heat loss, including placing the baby under a preheated radiant warmer, covering the baby in plastic wrapping, or using an exothermic mattress or prewarmed blankets or caps. In addition, the delivery of heated humidified gases in the DR and during neonatal transport might be helpful for infants requiring respiratory support at birth. ${ }^{24)}$ Warming and humidification of the inspired gas for respiratory support during neonatal resuscitation are not routinely performed in Korea. In a Brazilian study, the use of positive pressure ventilation with cold air in the DR and during transport increased the likelihood of hypothermia at NICU admission by 1.40 (95\% CI, 1.03-1.88) fold and 1.51 (95\% CI, 1.08-2.13) fold, respectively. ${ }^{17)}$ Although we could not determine whether the neonatal resuscitation policies of each center and their variation affects this high incidence of admission hypotension in Korea, our results will be useful for the application of evidence-based quality improvement activities in each center, aiming to reduce admission hypothermia in preterm infants.

The multivariate analysis in the present study indicated that the effect of gestational age alone was small but that birth weight was more strongly associated with admission hypothermia. Similar to the results of the multivariate analysis, the proportion of normothermic infants did not differ from 26 to 32 weeks of gestation in our study (Fig. 2). A mismatch between heat production and heat exchange with the ambient environment in the DR is determined by a large surface area and surface-to-weight ratio; thus, birth weight would be more closely associated with body temperature in preterm infants than gestational age.

This study has shown similar results to those of previous studies that have reported a significant correlation between admission hypothermia and mortality. ${ }^{5-9,15,17,18)}$ In 868 infants, including
VLBW infants from 18 centers in Malaysia, the OR for early death was $2.0(95 \% \mathrm{CI}, 1.2-3.4)$ for infants with temperatures $<36.5^{\circ} \mathrm{C}$ at NICU admission. ${ }^{15)}$ Laptook et al. ${ }^{7)}$ studied 5,277 VLBW infants and found that the risk of death increased $28 \%$ for every $1^{\circ} \mathrm{C}$ decrease in admission temperature. In a Brazilian cohort study of 1,764 infants less than 32 weeks of gestation, the likelihood of early death was 1.64 (95\% CI, 1.03-2.61)-fold higher in infants with temperatures $<35^{\circ} \mathrm{C}$ at NICU admission. ${ }^{17)}$ The adjusted OR of all death in our study was 1.86 (95\% CI, 1.22-2.82) for infants with hypothermia $<35.0^{\circ} \mathrm{C}$. The $\mathrm{OR}$ of early death ( $<28$ days) was higher than that of all death: 2.16 (95\% CI, 1.39-3.34) in these infants. Mortality was inversely related to admission temperature, but the relationship was not linear, but rather a second-order equation. A second-order curve indicates that the existence of the lowest mortality point for admission temperature and hyperthermia should be avoided for the best outcome for these vulnerable preterm infants. The lowest mortality point of temperature reflects the lowest oxygen consumption and best clinical outcomes. Higher than normal temperature has been previously associated with mortality and morbidities, ${ }^{25}$ but we could not confirm these associations in this study. This might be explained by the low number of infants with admission hyperthermia in our study.

The association between admission temperature and variable clinical outcomes is mostly consistent with the results of previous studies. ${ }^{6-8,14,18,23,26)}$ The association in our study between admission temperature and several morbidities, including BPD, sepsis and high-grade IVH, provides a potential link to the relationship between admission temperature and mortality. Even mild hypothermia, called cold stress $\left(36.0^{\circ} \mathrm{C}-36.4^{\circ} \mathrm{C}\right)$, increased the OR of sepsis to 1.27 (95\% CI, 1.05-1.54) compared to the normal temperature group in our study. Laptook et al. ${ }^{7}$ reported an 11\% increase in sepsis with each $1^{\circ} \mathrm{C}$ decrease in admission temperature. Whether late-onset sepsis remote from birth is causally linked to admission temperature is unclear. From adult studies showing that perioperative normothermia reduces postoperative infectious complications and since low temperature impairs chemotaxis, phagocytic engulfment and digestion of human leukocytes, we can speculate that low temperature has a strong impact on the immature and unstable immune function of these premature infants. ${ }^{27,28)}$

Our study has several limitations. First, we could not obtain the hospital-specific data from each NICU registered in the KNN. Not only did we not know the temperature of the DR of each center, but we also could not evaluate the policies for preventing hypothermia in the DR at each center. Second, our study collected data from the national cohort of VLBW infants; growth-restricted mature infants could be included in this cohort. To overcome this limitation, we analyzed data only for infants less than 33 weeks of gestational age. Third, body temperature was not collected using uniform methods, and we did not register the site at which the temperature was measured, which might have influenced the precision of the tem- 
perature. Recent studies have shown differences between axillary and rectal measurements but have also indicated that the differences are smaller in infants of younger gestational ages. ${ }^{29-32)}$ Fourth, 243 infants (5.2\%) had missing admission temperatures, and 300 infants (6.4\%) were excluded due to transfer to other hospitals, which could have potentially biased the results.

Whether the prevention of low temperatures at birth decreases mortality or whether low admission temperature is part of a casual path or simply a marker for an increase in the likelihood of mortality cannot be determined from this observational analysis. The strengths of our study included the use of data from a large nationwide dataset. The large amount of data also enabled us to evaluate the association between hypothermia at NICU admission and neonatal outcomes. The results of this observational cohort study demonstrate that minimizing the extent of temperature reduction at birth for premature infants remains challenging. This could be achieved by a combination of interventions that together aimed to counteract physical mechanisms of heat loss of preterm infants through interdisciplinary approaches involving obstetric and neonatal teams. In addition, increasing awareness about both the prevalence and the possible risks associated with hypothermia may be the motivation for improving clinical practices and abolishing hypothermia. ${ }^{33,34)}$ Additionally, consistent and standardized measurement of admission temperature should be an integral part of any quality improvement work targeting hypothermia after very preterm birth.

Despite the recent focus on preventing hypothermia after preterm birth, a large proportion of VLBW infants in Korea still have low temperatures at NICU admission. Admission hypothermia is associated with high mortality. In particular, there is a high correlation with early death before the age of 28 days. Admission hypothermia is also associated with high likelihoods of pulmonary hemorrhage, air-leak, BPD, pulmonary hypertension, sepsis, seizure, high-grade IVH, and advanced ROP. Constant and more integrative approaches are required to better maintain body temperature immediately after birth in this high-risk population.

\section{Conflicts of interest}

No potential conflict of interest relevant to this article was reported.

\section{Acknowledgments}

This research was supported by a research fund (2016-ER630702\#) from the Korea Centers for Disease Control and Prevention. We thank the administrative staff of the KNN and all the members of each participating center for their efforts in data collection.

\section{References}

1. Bhatt DR, White R, Martin G, Van Marter LJ, Finer N, Goldsmith JP, et al. Transitional hypothermia in preterm newborns. J Perinatol 2007; 27 Suppl 2:S45-7.

2. Bissinger RL, Annibale DJ. Thermoregulation in very low-birthweight infants during the golden hour: results and implications. Adv Neonatal Care 2010;10:230-8.

3. Maternal and Newborn Health/Safe Motherhood Unit. Thermal protection of the newborn: a practical guide. Geneva (Switzerland): World Health Organization, 1997.

4. American Academy of Pediatrics' Committee on Fetus and Newborn, American College of Obstetricians and Gynecologists' Committee on Obstetric Practice. Guidelines for perinatal care. 7th ed. Washington, DC: March of Dimes, 2012.

5. Hazan J, Maag U, Chessex P. Association between hypothermia and mortality rate of premature infants--revisited. Am J Obstet Gynecol 1991;164(1 Pt 1):111-2.

6. Laptook AR, Bell EF, Shankaran S, Boghossian NS, Wyckoff MH, Kandefer S, et al. Admission temperature and associated mortality and morbidity among moderately and extremely preterm infants. J Pediatr 2018;192:53-9.

7. Laptook AR, Salhab W, Bhaskar B; Neonatal Research Network. Admission temperature of low birth weight infants: predictors and associated morbidities. Pediatrics 2007;119:e643-9.

8. Lyu Y, Shah PS, Ye XY, Warre R, Piedboeuf B, Deshpandey A, et al. Association between admission temperature and mortality and major morbidity in preterm infants born at fewer than 33 weeks' gestation. JAMA Pediatr 2015;169:e150277.

9. Miller SS, Lee HC, Gould JB. Hypothermia in very low birth weight infants: distribution, risk factors and outcomes. J Perinatol 2011;31 Suppl 1:S49-56.

10. Wyllie J, Perlman JM, Kattwinkel J, Wyckoff MH, Aziz K, Guinsburg R, et al. Part 7: Neonatal resuscitation: 2015 International Consensus on Cardiopulmonary Resuscitation and Emergency Cardiovascular Care Science with Treatment Recommendations. Resuscitation 2015;95:e169-201.

11. Vohra S, Frent G, Campbell V, Abbott M, Whyte R. Effect of polyethylene occlusive skin wrapping on heat loss in very low birth weight infants at delivery: a randomized trial. J Pediatr 1999;134:547-51.

12. Vohra S, Roberts RS, Zhang B, Janes M, Schmidt B. Heat loss prevention (HeLP) in the delivery room: a randomized controlled trial of polyethylene occlusive skin wrapping in very preterm infants. J Pediatr 2004;145:750-3.

13. Knobel RB, Wimmer JE Jr, Holbert D. Heat loss prevention for preterm infants in the delivery room. J Perinatol 2005;25:304-8.

14. Costeloe K, Hennessy E, Gibson AT, Marlow N, Wilkinson AR. The EPICure study: outcomes to discharge from hospital for infants born at the threshold of viability. Pediatrics 2000;106:659-71.

15. Malaysian Very Low Birth Weight Study Group. A national study of risk factors associated with mortality in very low birthweight infants in the Malaysian neonatal intensive care units. J Paediatr Child Health 1997;33:18-25.

16. Chitty H, Wyllie J. Importance of maintaining the newly born temperature in the normal range from delivery to admission. Semin Fetal Neonatal Med 2013;18:362-8.

17. de Almeida MF, Guinsburg R, Sancho GA, Rosa IR, Lamy ZC, Martinez FE, et al. Hypothermia and early neonatal mortality in preterm infants. J Pediatr 2014;164:271-5.

18. Wilson E, Maier RF, Norman M, Misselwitz B, Howell EA, Zeitlin J, et al. Admission hypothermia in very preterm infants and neonatal mor- 
tality and morbidity. J Pediatr 2016;175:61-7.

19. Hahn WH, Chang JY, Chang YS, Shim KS, Bae CW. Recent trends in neonatal mortality in very low birth weight Korean infants: in comparison with Japan and the USA. J Korean Med Sci 2011;26:467-73.

20. Chung SH, Bae CW. Improvement in the survival rates of very low birth weight infants after the establishment of the Korean Neonatal Network: comparison between the 2000s and 2010s. J Korean Med Sci 2017;32:1228-34.

21. Chang YS, Ahn SY, Park WS; Committee on Program and Planning and Advisory Committee of Korean Neonatal Network. The establishment of the Korean Neonatal Network (KNN). Neonatal Med 2013;20: 169-78.

22. Papile LA, Burstein J, Burstein R, Koffler H. Incidence and evolution of subependymal and intraventricular hemorrhage: a study of infants with birth weights less than 1,500 gm. J Pediatr 1978;92:529-34.

23. Jang JH, Shin SH, Woo HK, Choi EK, Song IG, Shin SH, et al. The association between admission hypothermia and neonatal outcomes in very low birth weight infants. Neonatal Med 2016;23:183-9.

24. Meyer MP, Hou D, Ishrar NN, Dito I, te Pas AB. Initial respiratory support with cold, dry gas versus heated humidified gas and admission temperature of preterm infants. J Pediatr 2015;166:245-50.

25. Perlman JM. Hyperthermia in the delivery: potential impact on neonatal mortality and morbidity. Clin Perinatol 2006;33:55-63.

26. Costeloe KL, Hennessy EM, Haider S, Stacey F, Marlow N, Draper ES. Short term outcomes after extreme preterm birth in England: comparison of two birth cohorts in 1995 and 2006 (the EPICure studies).
BMJ 2012;345:e7976.

27. van Oss CJ, Absolom DR, Moore LL, Park BH, Humbert JR. Effect of temperature on the chemotaxis, phagocytic engulfment, digestion and 02 consumption of human polymorphonuclear leukocytes. J Reticuloendothel Soc 1980;27:561-5.

28. Kurz A, Sessler DI, Lenhardt R. Perioperative normothermia to reduce the incidence of surgical-wound infection and shorten hospitalization. Study of Wound Infection and Temperature Group. N Engl J Med 1996;334:1209-15.

29. Lantz B, Ottosson C. Using axillary temperature to approximate rectal temperature in newborns. Acta Paediatr 2015;104:766-70.

30. Charafeddine L, Tamim H, Hassouna H, Akel R, Nabulsi M. Axillary and rectal thermometry in the newborn: do they agree? BMC Res Notes 2014;7:584

31. Craig JV, Lancaster GA, Williamson PR, Smyth RL. Temperature measured at the axilla compared with rectum in children and young people: systematic review. BMJ 2000;320:1174-8.

32. Hissink Muller PC, van Berkel LH, de Beaufort AJ. Axillary and rectal temperature measurements poorly agree in newborn infants. Neonatology 2008;94:31-4.

33. Russo A, McCready M, Torres L, Theuriere C, Venturini S, Spaight M, et al. Reducing hypothermia in preterm infants following delivery. Pediatrics 2014;133:e1055-62.

34. Pinheiro JM, Furdon SA, Boynton S, Dugan R, Reu-Donlon C, Jensen S. Decreasing hypothermia during delivery room stabilization of preterm neonates. Pediatrics 2014;133:e218-26. 